\title{
Fundamental understanding of the interaction of continuous wave laser with aluminium
}

\author{
Júlio Coroado $^{1} \cdot$ Sónia Meco $^{1}$ - Stewart Williams ${ }^{1}$ - Supriyo Ganguly ${ }^{1}$. \\ ${\text { Wojciech } \text { Suder }^{1} \cdot \text { Luísa Quintino }^{2} \cdot \text { Eurico Assunção }}^{2}$
}

Received: 13 February 2017 / Accepted: 19 June 2017 / Published online: 13 July 2017

(C) The Author(s) 2017. This article is an open access publication

\begin{abstract}
In welding, the depth of penetration, weld profile and the corresponding thermal cycle are the three basic outcomes that a user wishes to control flexibly. In laser welding applications, controlled application of power and energy density is the key to achieve predictable control of these characteristics. Creation of an analytical model is an important step towards understanding the underpinning science of laser metal interaction in controlling the depth, bead geometry and thereby temperature profile of a weld. The "power factor model", which correlates the power applied per unit length to the laser metal interaction time, has been originally developed and validated for mild steel, guides a user on the selection laser system parameters, to achieve specific weld profile. This study is performed to extend the power factor-interaction time model to aluminium alloys by understanding the underpinning laser aluminium interaction parameters in terms of power density, interaction time, specific point energy and their correlation with the weld bead profiles. Although the power factor and interaction time showed a rectangular hyperbolic relationship, as observed in low carbon steel, for a specific weld depth and profile, the absolute magnitude and the characteristic profile of the curve is different due to the intrinsic differences in physical and thermal properties of aluminium as compared to steel. It was shown that identical depth of penetration but different weld metal profile can be obtained for a specific
\end{abstract}

Júlio Coroado

j.c.coroado@cranfield.ac.uk

1 Welding Engineering and Laser Processing Centre, Cranfield University, Cranfield MK43 0AL, UK

2 Instituto Superior Técnico, Universidade de Lisboa, Av. Rovisco Pais, 1049-001 Lisboa, Portugal beam diameter for a range of power and travel speed by keeping the energy input per unit length constant.

Keywords Power factor model $\cdot$ Interaction time $\cdot$ Depth of penetration $\cdot$ Laser welding $\cdot$ Laser beam diameter $\cdot$ Weld width

\section{Introduction}

Joining processes and procedures, using laser as power source is undergoing rapid development with new applications, extend to new materials and new joint design. The heat source for laser welding may be a carbon dioxide gas $\left(\mathrm{CO}_{2}\right)$ laser, YAG laser, diode laser (LD), LD pumped solid laser, fibre laser and disc laser. Recently, there has been a rapid increase in the use of the fibre laser, which has the flexibility of being conducted by fibre and can be miniaturized with high beam quality and high efficiency, as a welding heat source with increased power and high power density. High power fibre lasers can be used for deep penetration welding in a diversity of materials due to their capability to be narrowly focused, and the fibre delivery system provides the necessary flexibility on the positioning of the beam [1].

Laser welding is extremely productive for the construction of aluminium structures, such as bridges, buildings and transport industry. The laser welding of aluminium alloy is a very promising technique process, and it has a high potential due to the high laser beam energy density that can result in a high penetration/width ratio, compared to other fusion welding processes. Laser can also have a very precise heat input control, and with higher power density, it may result in high temperature gradients and very small heat-affected zones [2]. However, due to its high reflectivity and higher thermal conductivity, aluminium alloy also possesses some difficulties in 
laser processing [3]. For an A5052 aluminium alloy, it has been demonstrated that at $10 \mathrm{~kW}$ of laser power, its absorption was over $80 \%$ at less than $100 \mathrm{~mm} / \mathrm{s}$ speeds and was reduced to less than $20 \%$ at $300 \mathrm{~mm} / \mathrm{s}$ [3]. Tensile strength and ductility is also degraded by the magnesium losses in the aluminium alloy. For the same alloy, it was shown that the strength of the weld can decrease below $66 \%$ of the parent metal once the magnesium content decreased up to $50 \%$ in the fusion zone [4]. A vapour channel, also known as plume, is formed mainly due to the vaporization of the base material. Solute atoms, e.g., magnesium and other low vaporization point elements, mainly affect the vapour pressure. The plume instability is one of the most important reasons for keyhole fluctuation mechanism, leading to welding defects, such as spatters and pores [5]. A correlation between the vapour plume centre position and the depth of penetration was established by Brock et al. [6]. It has been observed that the vapour plume inclines in the direction of the melt pool as the penetration depth increases. It was suggested that by evaluating the shape of the vapour plume during the welding process, a closed loop control system could be implemented to achieve a desired penetration depth and avoid welding defects.

The versatility of lasers is demonstrated by the application on different materials with a huge flexibility in terms of the energy delivered to the workpiece. The size and shape of the beam (axial [7] and radial [8]) associated with different combinations of power and travel speed generate different power and energy density and the overall energy application within the laser spot. These parameters affect the flow dynamics of the weld pool during the process [9] and have a direct influence on the final weld seam, including the depth of penetration, which is one of the main outputs that users wish to control. However, for high welding speed and power, the turbulence in the melt pool increases, increasing the frequency of spatter ejection and consequent metal loss [10]. Depending on the processing conditions, there are two main operational regimes: conduction mode and keyhole mode. The latter is a relatively unstable process, used for deep penetration depth and a narrow heat-affected zone, whilst no vaporization occurs in conduction laser welding, making this a very stable process that allows control of the heat delivered to the workpiece. Both processing conditions were investigated by Assuncao and Williams [11]. Several inspection systems have been developed for laser welding monitoring of the keyhole and vapour plume [12] based on online-x-ray [13], acoustic [14], thermal and visual techniques [15], which have high influence on the final quality of the weld [16]. Using a high-speed coaxial video camera, it was possible to analyse the keyhole's behaviour during the welding process. When it is open at the bottom, it looks like a black spot, whereas when the bottom aperture is closed, it emits strong thermal radiation. Kim et al. [9] suggested that the brightening was an indication of intensive heating by the laser beam. The vapour pressure also plays a fundamental role on the keyhole stability [17]. The authors showed that the right balance between dynamic pressure, closing pressure and keyhole pressure allows defining different parameter regimes. It was also found that for large keyhole diameters, the keyhole pressure is determined by the ambient pressure, whereas at very small diameters, the closing pressure is dominant. Luo et al. found that deeper welds could be achieved by lowering the ambient below atmospheric pressure [18]. Kawahito et al. [3] demonstrated that the absorption conditions can be changed according to the processing parameters selected which directly affects the operational regime of the welding process.

In summary, achieving a certain weld metal penetration depth could be achieved by a different set of variable parameters, e.g. power, travel speed and beam diameter, by understanding the interdependence of the variables. However, mutual interaction of the variable parameters would result in different weld bead profile, i.e. the width of the weld would be different for identical penetration depth. Therefore, for a specific penetration depth, the weld profiles can be widely different which would alter the heat-affected zone dimension and in turn the mechanical properties of the graded structure. This gives the desired flexibility in laser joining; however, a complete understanding of the interaction between laser and the substrate alloy is vital to exploit the flexibility in joint formation. The power factor model, developed for keyhole mode, gives the optimal laser parameter settings for laser power and travel speed for a given beam diameter, to obtain a specific weld profile. It was previously developed at Cranfield University by Suder and Williams [19], first for low carbon steel and then for titanium alloys. This study focusses on developing the laser alloy interaction for aluminium 5083 alloy which is one of the widely used cast alloys for general applications.

In this study, it has been intended to create a processing window for laser system parameters which allows choice of a laser power and travel speed to obtain depth of penetration and weld width suitable for an application. An analytical model would enable understanding the laser-alloy interaction for aluminium and develop the necessary underpinning understanding to transfer processing parameters to achieve similar results using different laser systems.

\section{Mathematical formulation of the model}

\subsection{Definition of the fundamental laser material interaction parameters}

Interaction of a laser beam with a workpiece is determined by the power density $\left(q_{p}\right)$, time of irradiation and the size of the heat source on the workpiece. The analysis of the welding results was made using the fundamental laser material 
interaction parameters (FLMIP), i.e. the power density, interaction time $\left(t_{i}\right)$ and specific point energy $\left(E_{S P}\right)$, since these parameters can be used to replicate the welding process in different laser systems [20,21]. The system parameters, used to calculate the FLMIP, are the following: laser output power $\left(P_{L}\right)$, welding speed $(v)$ and beam diameter $(d)$.

The power density is determined as the ratio of the laser output power to the area of laser spot on the surface $\left(A_{S}\right)$, which for a circular beam diameter is given by Eq. (1):

$q_{p}=P_{L} / A_{S}\left[\mathrm{MW} \mathrm{cm}^{-2}\right]$

Interaction time defines the time, in which a particular point is exposed to the laser beam in the weld centreline, whilst the beam is moving with a constant speed. The interaction time is defined as the ratio of the beam diameter in welding direction to the welding speed, given by Eq. (2):

$t_{i}=d / \mathrm{v}[\mathrm{s}]$

The energy delivered to any specific point on the weld centreline is called the specific point energy, and it is equal to the product of power density, interaction time and the area of the laser spot on the surface, as given by Eq. (3):

$E_{S P}=q_{p} t_{i} A_{s}=P_{L} \mathrm{~d} / \mathrm{v}[\mathrm{J}]$

\subsection{Definition of power factor}

The power factor model was developed by Suder and Williams [19]. They reported the influence of the fundamental laser material interaction parameters on low carbon steel. The results suggested that the power density and the specific point energy control the depth of penetration whilst the interaction time controls the weld width. Considering the first two parameters and their relationship with the beam diameter, the specific point energy (linearly dependent on the beam diameter) and the power density (inverse square of the beam diameter), the depth of penetration should be proportional to the ratio of the laser power to the beam diameter. From this, constant depth of penetration curves, independent of the beam size, was generated. Thus, the power factor $P_{F}$ was defined by the product of power density and beam diameter, which also corresponds to the ratio of the laser power to beam diameter, as given by Eq. (4):

$P_{F}=q_{p} d=P_{L} / d\left[\mathrm{~W} \mathrm{~m}^{-1}\right]$

\section{Experimental set-up}

The material used was 5083 aluminium alloy with the following dimensions: $250 \times 200 \times 12 \mathrm{~mm}$. The chemical composition is shown in Table 1.

An IPG YLR-8000 CW multimode fibre laser with a maximum power of $8 \mathrm{~kW}$ was used in the experiments presented in this study. The laser beam was delivered through an optical fibre with $300 \mu \mathrm{m}$ of diameter and collimated with a $125-\mathrm{mm}$ focal length lens. A set of focusing lenses with focal lengths of 200, 250 and $300 \mathrm{~mm}$ were used aiming to achieve different beam diameters. The characteristics of the laser beam, such as beam diameter and focus position, were measured by means of a Primes $\mathrm{GmbH}$ focus monitor. All laser beams exhibited a top-hat intensity distribution at the focal point. The beam diameter at the focal position for each set of focusing lens is shown in Table 2.

In all experiments, the welding process was carried out at the focal point, i.e. with the laser beam focused on the surface of the material, as shown in Fig. 1. The laser head was attached to a Fanuc robot with an angle of $10^{\circ}$, to protect the laser system from laser back reflection. The substrate was clamped on a linear stage which was used to produce linear bead on plate welds.

Pure shield argon was used as shielding gas with a flow rate of $30 \mathrm{l} / \mathrm{min}$. In order to measure the depth of penetration and weld width, all welds were cross-sectioned in two different positions, polished and examined under the optical microscope. A standard procedure was used to prepare the metallographic samples. Keller's was used to etch the welds and reveal the microstructure. The macrographs were analysed to determine weld width and depth of penetration and measured using an Carl Zeiss Axio Vision 4.8 image analysis software (https://www.zeiss.com/microscopy/int/products/microscopesoftware/axiovision.html). The depth of penetration measured considers the distance between the material surface and the bottom of the fusion zone. The experimental error was calculated based on the difference of the penetration depth
Table 1 Chemical composition of aluminium 5083

\begin{tabular}{lllllllll}
\multicolumn{1}{l}{ Chemical composition in $\%$ wt of 5083} & \multicolumn{1}{l}{ aluminium alloy } \\
\hline $\mathrm{Si}$ & $\mathrm{Fe}$ & $\mathrm{Cu}$ & $\mathrm{Mn}$ & $\mathrm{Mg}$ & $\mathrm{Zn}$ & $\mathrm{Ti}$ & $\mathrm{Cr}$ & $\mathrm{Al}$ \\
$\mathrm{Max} 0.4$ & Max 0.4 & Max 0.10 & $0.4-1.0$ & $4.0-4.9$ & $\mathrm{Max} 0.1$ & $0.05-0.25$ & $0.05-0.25$ & Bal. \\
\hline
\end{tabular}


Table 2 Beam properties of different optical set-ups

\begin{tabular}{lllllc}
\hline $\begin{array}{l}\text { Diameter of } \\
\text { delivery fibre }(\mu \mathrm{m})\end{array}$ & $\begin{array}{l}\text { Collimation } \\
\text { lens }(\mathrm{mm})\end{array}$ & $\begin{array}{l}\text { Focusing } \\
\text { lens }(\mathrm{mm})\end{array}$ & $\begin{array}{l}\text { Beam diameter } \\
(\mathrm{d})(\mathrm{mm})\end{array}$ & $\begin{array}{l}\text { Rayleigh } \\
\text { length }(\mathrm{mm})\end{array}$ & $\begin{array}{l}\text { Divergence } \\
\text { angle }(\mathrm{mrad})\end{array}$ \\
\hline 300 & 200 & 0.49 & 4.2 & 118.7 \\
& \multirow{2}{*}{125} & 250 & 0.61 & 6.5 & 94.1 \\
& 300 & 0.75 & 9.6 & 78.0 \\
\hline
\end{tabular}

observed between the first and second position of the crosssections for the same welding parameters. As the laser absorptivity by the material changes with the welding mode, i.e. conduction, keyhole and mixed mode [11], only the keyhole welds were considered in this work.

\section{Methodology}

\subsection{Effect of power density and specific point energy}

To investigate the effect of power density and specific point energy on the depth of penetration, a set of bead-on-plate welds with different beam diameters of $0.49,0.61$ and $0.75 \mathrm{~mm}$ were applied. For each beam diameter, different combinations of power and welding speed were used, resulting in a range of power density from 0.84 to $2.3 \mathrm{MW} /$ $\mathrm{cm}^{2}$ and specific point energy from 6.1 to $174 \mathrm{~J}$, according to Eqs. (1) and (3), respectively. Since the power factor is dependent of specific point energy and power density, this section intends to prove that the same depth can be achieved with high specific point energy and low power density or vice versa. The set of parameters used for different beam diameters is shown in Table 3.

\subsection{Effect of interaction time and power factor}

The extension of the power factor model for aluminium was performed using a set of bead-on-plate welds. The effect on the depth of penetration and weld width was investigated in two steps: First, for a given $d$ of $0.61 \mathrm{~mm}$, different combinations of power factor and interaction time were tested, by varying laser power and travel speed, respectively. These combinations resulted in a range of interaction time from 2.0 to $50 \mathrm{~ms}$ and a range of power factor from 4.0 to $12 \mathrm{MW} / \mathrm{m}$, according to Eqs. (2) and (4), respectively. The widths and the depths of penetration of the fusion of the welds were

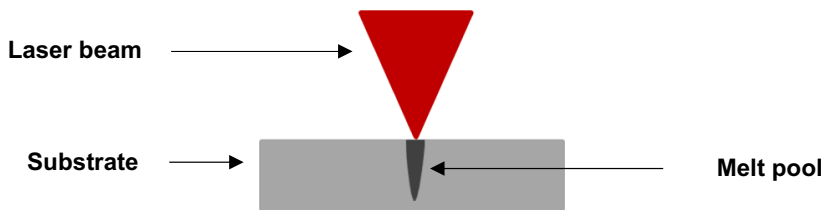

Fig. 1 Schematic representation of a bead on plate weld with laser beam focused on the material surface examined and only three depths of penetration were considered $(2.0,4.0$ and $6.0 \mathrm{~mm})$, to make the representation of the results easier. Second, the same power factor and interaction time values were used with different beam diameters ( 0.49 and $0.75 \mathrm{~mm}$ ), adjusting laser power and travel speed accordingly to Eqs. (2) and (4), respectively. It is intended to prove in this section that the same results can be obtained independently of the beam diameter used. All parameters are shown in Table 4.

\section{Results and discussion}

\subsection{Effect of power density and specific point energy}

Different combinations of laser power and travel speed were tested for one beam diameter of $0.61 \mathrm{~mm}$. The results for depth of penetration of 2.0, 4.0 and $6.0 \mathrm{~mm}$ are plotted as a function of power density and specific point energy in Fig. 2. There is a strong correlation between power density and specific point energy for different values of depth of penetration. Welds with similar depth of penetration can be achieved with either high power density, if the specific point energy is low (Fig. 2a)), or with low power density, if the specific point energy is high (Fig. 2c)). To achieve the weld represented in Fig. 2c, power density needs to be reduced by means of laser power, considering constant beam diameter. On the other hand, a longer interaction time is required to achieve higher specific point energy. Therefore, for constant beam diameter, the travel speed is reduced according to Eq. (2). This implies that the weld width gets wider from point a to c.

The same trend between power density and specific point energy is observed when the welds are produced with different beam diameters. Figure 3 shows the connection between power density and specific point energy, correspondent to the

Table 3 Set of parameters used for different combinations of power density and specific point energy

\begin{tabular}{llllll}
\hline $\begin{array}{l}\text { Beam } \\
\text { diameter } \\
(\mathrm{mm})\end{array}$ & $\begin{array}{l}\text { Power } \\
(\mathrm{kW})\end{array}$ & $\begin{array}{l}\text { Travel } \\
\text { speed } \\
(\mathrm{m} / \mathrm{min})\end{array}$ & $\begin{array}{l}\text { Interaction } \\
\text { time }(\mathrm{ms})\end{array}$ & $\begin{array}{l}\text { Power } \\
\text { density } \\
\left(\mathrm{MW} / \mathrm{cm}^{2}\right)\end{array}$ & $\begin{array}{l}\text { Specific } \\
\text { point } \\
\text { energy }(\mathrm{J})\end{array}$ \\
\hline$d$ & $\mathrm{P}_{\mathrm{L}}$ & $v$ & $\mathrm{t}_{\mathrm{i}}$ & $\mathrm{q}_{\mathrm{p}}$ & $\mathrm{E}_{\mathrm{SP}}$ \\
0.49 & $2.4-4.0$ & $1.0-4.0$ & $7.3-29$ & $1.3-2.1$ & $18-95$ \\
0.61 & $3.0-7.0$ & $0.73-18$ & $2.0-50$ & $1.0-2.3$ & $6.1-174$ \\
0.75 & $3.7-6.2$ & $1.5-6.0$ & $7.3-29$ & $0.84-1.4$ & $27-107$ \\
\hline
\end{tabular}


Table 4 Set of parameters used for different combinations of interaction time and power factor

\begin{tabular}{llcll}
\hline $\begin{array}{l}\text { Beam } \\
\text { diameter } \\
(\mathrm{mm})\end{array}$ & $\begin{array}{l}\text { Power } \\
(\mathrm{kW})\end{array}$ & $\begin{array}{l}\text { Travel speed } \\
(\mathrm{m} / \mathrm{min})\end{array}$ & $\begin{array}{l}\text { Interaction } \\
\text { time }(\mathrm{ms})\end{array}$ & $\begin{array}{l}\text { Power factor } \\
(\mathrm{MW} / \mathrm{m})\end{array}$ \\
\hline $\mathrm{d}$ & $\mathrm{P}_{\mathrm{L}}$ & $v$ & $\mathrm{t}_{\mathrm{i}}$ & $\mathrm{P}_{\mathrm{F}}$ \\
0.49 & $2.4-4.0$ & $1.0-4.0$ & $7.3-29$ & $4.9-8.2$ \\
0.61 & $2.4-7.0$ & $0.73-18$ & $2.0-50$ & $4.0-12$ \\
0.75 & $3.7-6.2$ & $1.5-6.0$ & $7.3-29$ & $4.9-8.2$ \\
\hline
\end{tabular}

welds with $4.0 \mathrm{~mm}$ of penetration produced with beam diameters of $0.49,0.61$, and $0.75 \mathrm{~mm}$. As the beam diameter is variable, power and travel speed have to be adjusted to achieve the required level of power density and specific point energy, respectively, to keep the penetration constant. Thus, specific point energy can be varied by interaction time and beam diameter, according to Eq. (3). As beam diameter varies, the specific point energy of Fig. 3a-c varied only with beam diameter, instead of interaction time. Since the interaction time is constant (29 ms), the weld width is the same for all of them. This means that, when different beam diameters are used, the trade-off between specific point energy and power density only predicts the depth of penetration but not the weld width, as previously demonstrated for mild steel by Suder and Williams [19].

To achieve different depths of penetration, several combinations of parameters can be used. This can be an advantage because the laser user can choose the parameters according to the productivity or quality required. On the other hand, it complicates the selection of the right set of parameters to achieve a desired depth of penetration and weld width for different laser systems.

Due to the effect of the beam diameter, power and travel speed on the weld profile, it was necessary to create a model able to make the depth of penetration and the weld width independent from one parameter. The weld width is independent of the beam diameter; it is controlled by the interaction time and thermal properties of the material. Thus, the effect of beam diameter and travel speed on the weld profile can be defined by one parameter: the interaction time, according to Eq.(2). The dependence of the depth of penetration from power density and specific point energy can also be represented by only one parameter: the power factor, according to Eq.(4). The power factor model, previously established for mild steel, was shown in Fig. 4. It is evident that all data follows the same trend for different beam diameters, proving its independence from the depth of penetration. A certain combination of power factor and interaction time implies a certain depth of penetration. This model can only be applied in aluminium if the same trend lines of Fig. 4 are also achievable.

\subsection{Effect of interaction time and power factor}

It was shown in Sect. 5.1 that a specific depth of penetration is achieved by a trade-off between power density and specific point energy for different beam diameters. To extend the application of the model to aluminium, it is necessary to investigate if the dependence of depth of penetration on laser power, travel speed and beam diameter can be represented by power factor and interaction time, as previously established for mild steel [19].

Starting for only one beam diameter of $0.61 \mathrm{~mm}$, power factor and interaction time are strongly related with the depth of penetration, as shown in Fig. 5. The evolution of the weld profile for a constant depth of penetration of $6 \mathrm{~mm}$ is also shown in the same figure. Three different penetrations of 2.0, 4.0 and $6.0 \mathrm{~mm}$ can be achieved adjusting the power factor and the interaction time. However, the independence of the model from the beam diameter can only be proved if,
Fig. 2 Power density for depths of penetration of 2.0, 4.0 and $6.0 \mathrm{~mm}$ as function of specific point energy, using beam diameters of $0.61 \mathrm{~mm}$

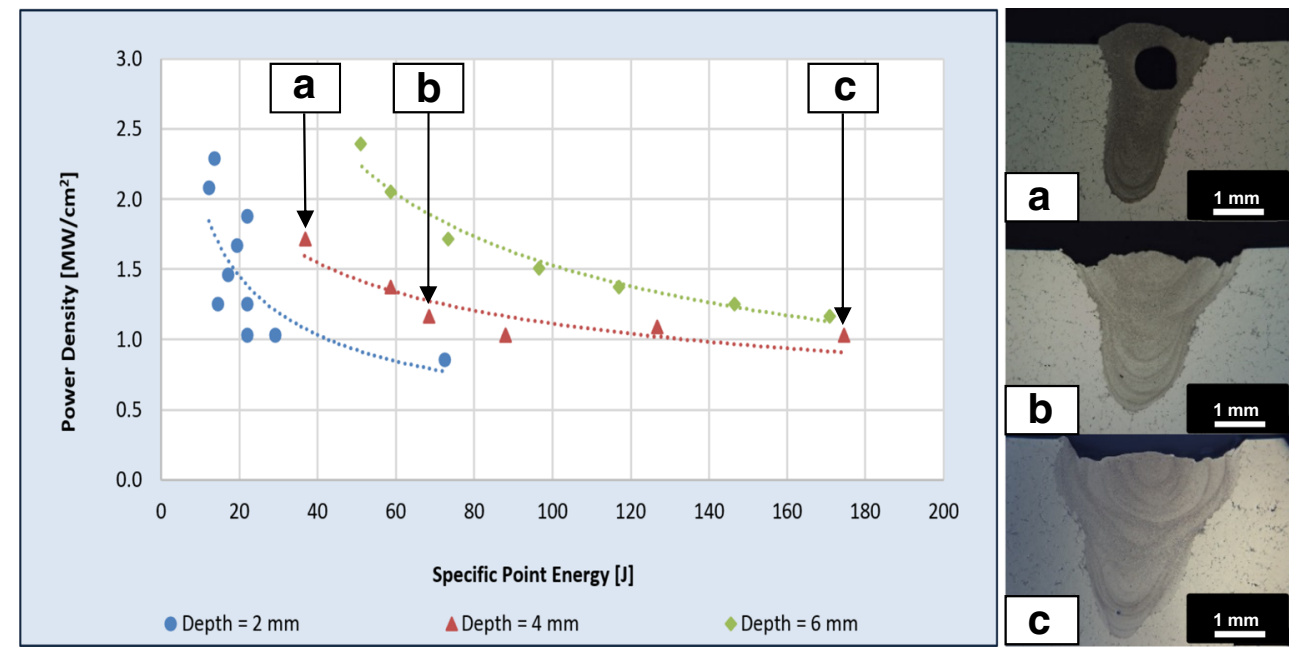


Fig. 3 Power density for depth of penetration of $4.0 \mathrm{~mm}$ as function of specific point energy, using beam diameters of $0.49,0.61$ and $0.75 \mathrm{~mm}$
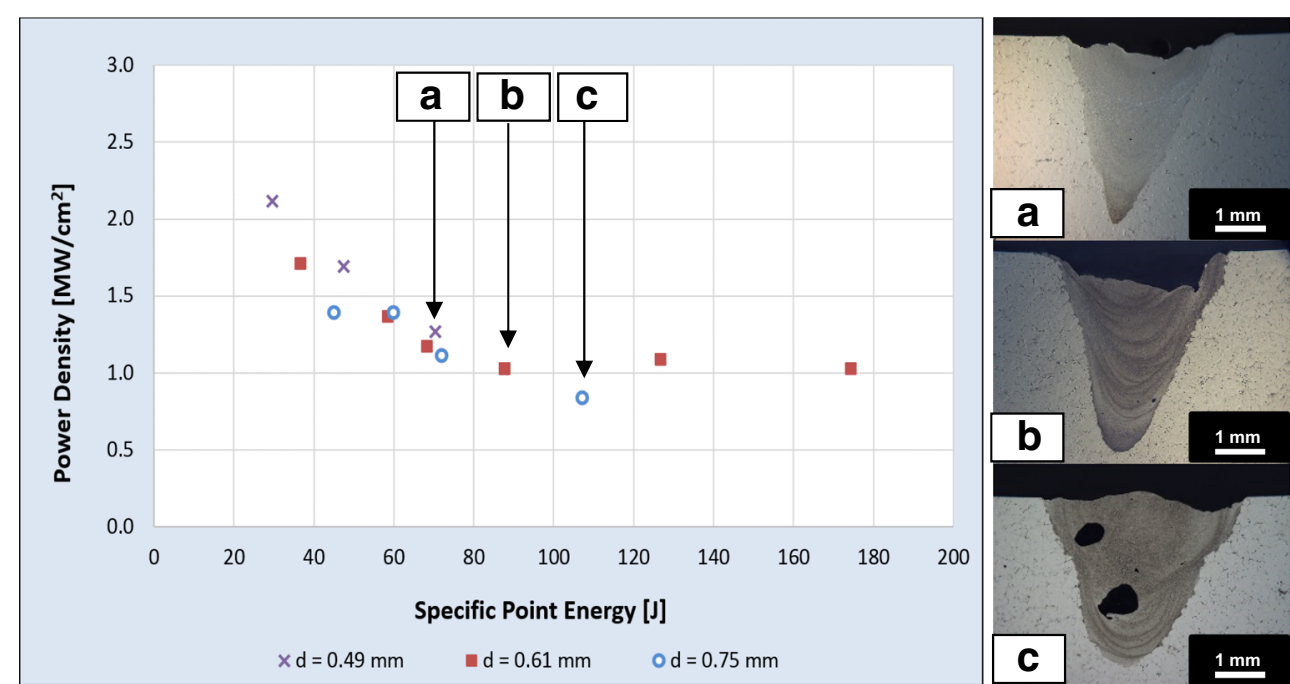

using different beam diameters, the same trend lines are achievable by adjusting the values of power and travel speed to create identical laser metal interaction conditions.

Analysing Fig. 5a, it is possible to conclude that the process is less stable for shorter interaction times and higher power factors, since entrapment of gas is visible, which means the keyhole is solidifying faster than the evolution of gas ion entrapments. Nevertheless, the process is more productive for these parameters, since shorter interaction time means higher travel speed, for constant beam diameter, according to Eq. 2. On the other hand, the welding speed is lower at higher interaction time, leading to less productivity. It can be seen in Fig. $5 c$ that the overall weld area is larger, which also means the stringency of the fit-up tolerance is less. This evaluation has been done based on the comparison between the two cross-sections for each welding parameter, as described in Sect. 3, which demonstrated high consistency.

The effect of the beam diameter on the depth of penetration for an interaction time and a constant power factor is shown in Fig. 6. For this range of beam diameters, a constant depth of penetration is demonstrated for constant interaction times.

The weld profiles of Fig. 6 are shown in Fig. 7. Comparing Fig. $7 \mathrm{a}-\mathrm{c}$ with Fig. $7 \mathrm{~d}-\mathrm{f}$, it is evident that it is concluded that the power factor affects the depth of penetration, for constant values of interaction time. Increasing the power factor from 4.9 to $6.6 \mathrm{MW} / \mathrm{m}$ and using a constant interaction time of $7.3 \mathrm{~ms}$, the depth of penetration increased from 2.0 to $3.0 \mathrm{~mm}$. However, the average weld width in all the welds is $2.5 \mathrm{~mm}$, which means that the power factor principally influence the depth of penetration. Comparing Fig. 7d-f with Fig.
Fig. 4 Power factor and interaction time required for depths of penetration of 8,6 and $4 \mathrm{~mm}$, in low carbon steel for a range of beam diameters between 0.38 and $0.78 \mathrm{~mm} \mathrm{[19]}$

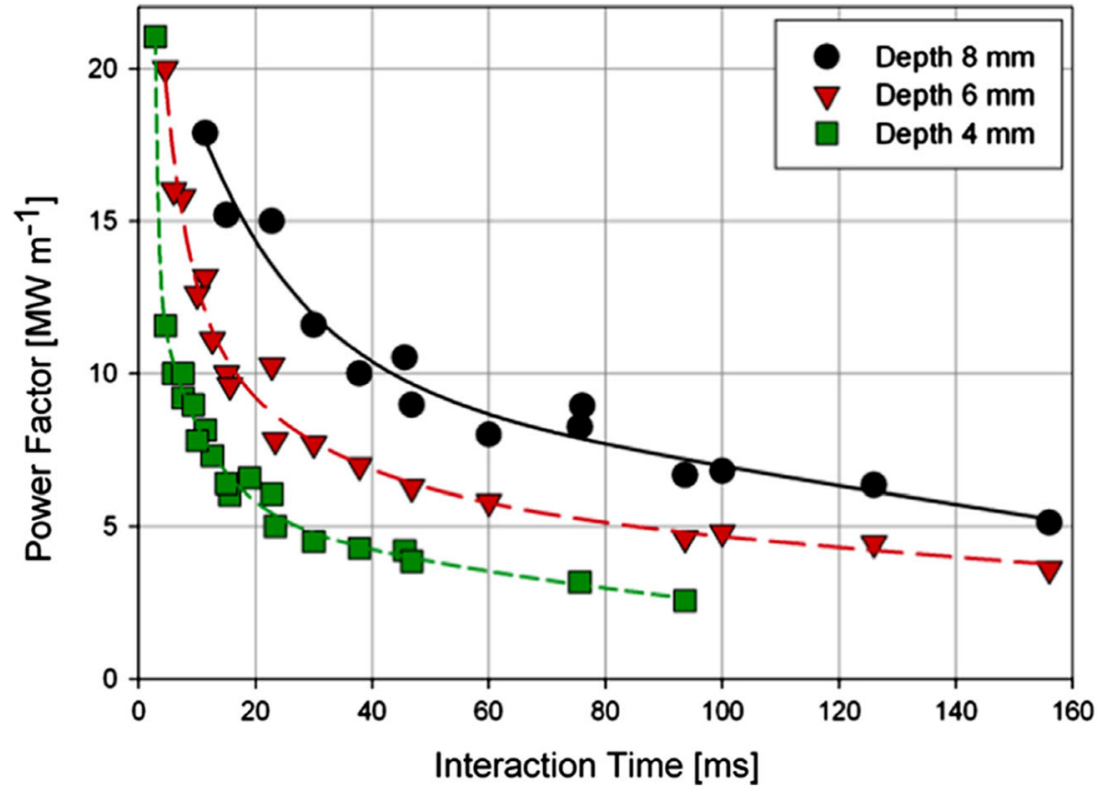


Fig. 5 Power factor for depths of penetration of 2.0, 4.0 and $6.0 \mathrm{~mm}$ as function of interaction time for a beam diameter of $0.61 \mathrm{~mm}$
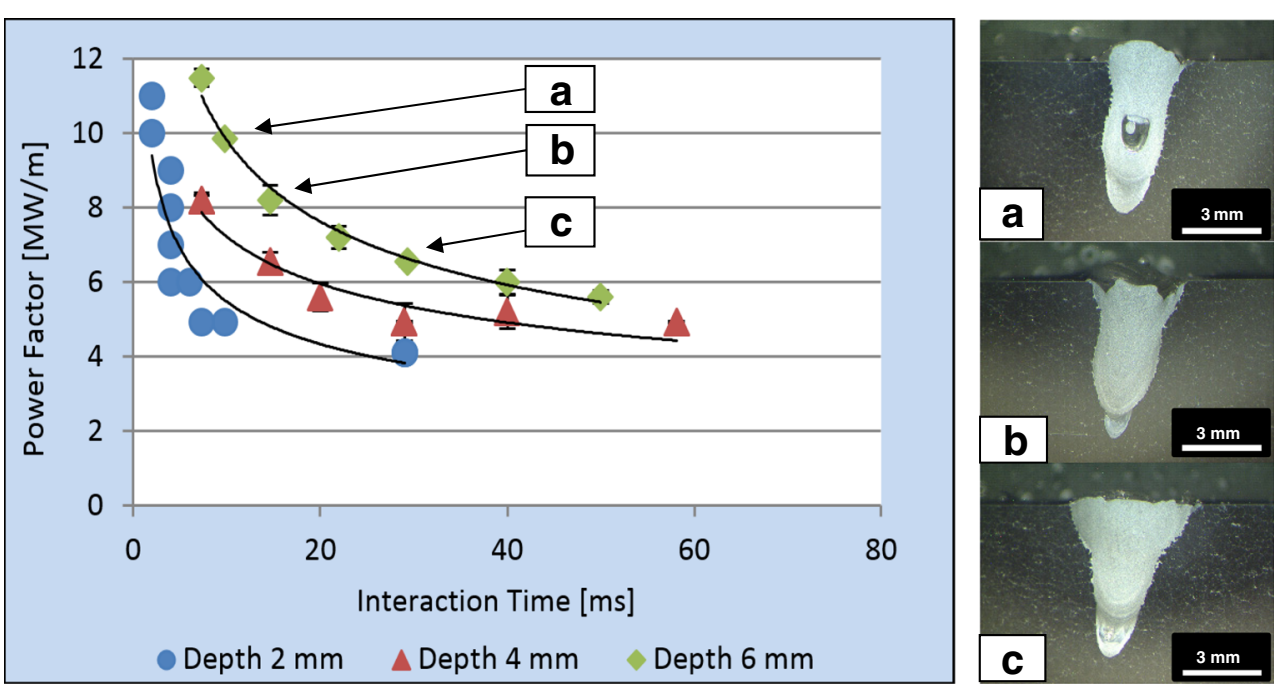

$7 \mathrm{~g}-\mathrm{i}$, for a constant power factor of $6.6 \mathrm{MW} / \mathrm{m}$, increasing the interaction time from 7.3 to $14.7 \mathrm{~ms}$, the average weld width increased from 2.5 to $3.6 \mathrm{~mm}$. On the other hand, the depth of penetration also increased from 3 to $4.0 \mathrm{~mm}$, once the specific point energy increased, according to Eq. (3).

There are two main factors responsible for changing the shape and properties of the welds: phenomenological and operational [22]. In the first factor is included the fluctuations of keyhole and melt pool, which can induce a difference of $10 \%$ on the total depth of penetration for partially penetrated welds, as previously reported by Suder and Williams [19] and also observed in Fig. 6. The low boiling point elements, high thermal conductivity and low viscosity are some of the reasons that make the keyhole laser welding of aluminium an unstable process causing also porosity and blow holes [23], which matches with Fig. 7b, i, respectively. However, the porosity level can also be improved by changing the incident angle of the laser, which is considered as an operating factor. For a forward incident angle of laser irradiation of $50^{\circ}$, Katayama et al. [24] found no porosity in the aluminium welds through an X-ray inspection. Nevertheless, for an incident angle of $10^{\circ}$ (the same used in this study), some porosity was observed. It was also reported that undercut and bead irregularity can be created by the non-optimized shielding device and flow rate. Using argon shielding gas with a flow rate of $15 \mathrm{l} / \mathrm{min}$, rough surfaces and undercut was shown. The same shielding gas was used in this study but with a flow rate of $30 \mathrm{l} / \mathrm{min}$, which was not enough to avoid undercut and bead irregularity, as shown in Fig. 7.

Based on data from Figs. 6 and 7, it was proven that the same depths of penetration can be achieved by changing the beam diameter, keeping the power factor and the interaction time constants, by adjusting travel speed and power. Thus, the three different depths of penetration shown in Fig. 5 can also be achieved using two more beam diameters ( 0.49 and $0.75 \mathrm{~mm}$ ). The result is the graph in Fig. 8. The characteristic variation follows a rectangular hyperbolic relationship between power factor and interaction time, as observed before (Fig. 4).

The shape of the weld-bead is determined by the laser welding input parameters. Despite the same penetration of Fig. $8 \mathrm{a}-\mathrm{c}$, the weld width is becoming wider along the trend line for higher values of interaction time and lower values of power factor, as shown previously in Fig. 5. This figure
Fig. 6 Effect of the beam diameter on the depth of penetration at different interaction times and a constant power factor. a $4.9 \mathrm{MW} / \mathrm{m}$. b $6.6 \mathrm{MW} / \mathrm{m}$
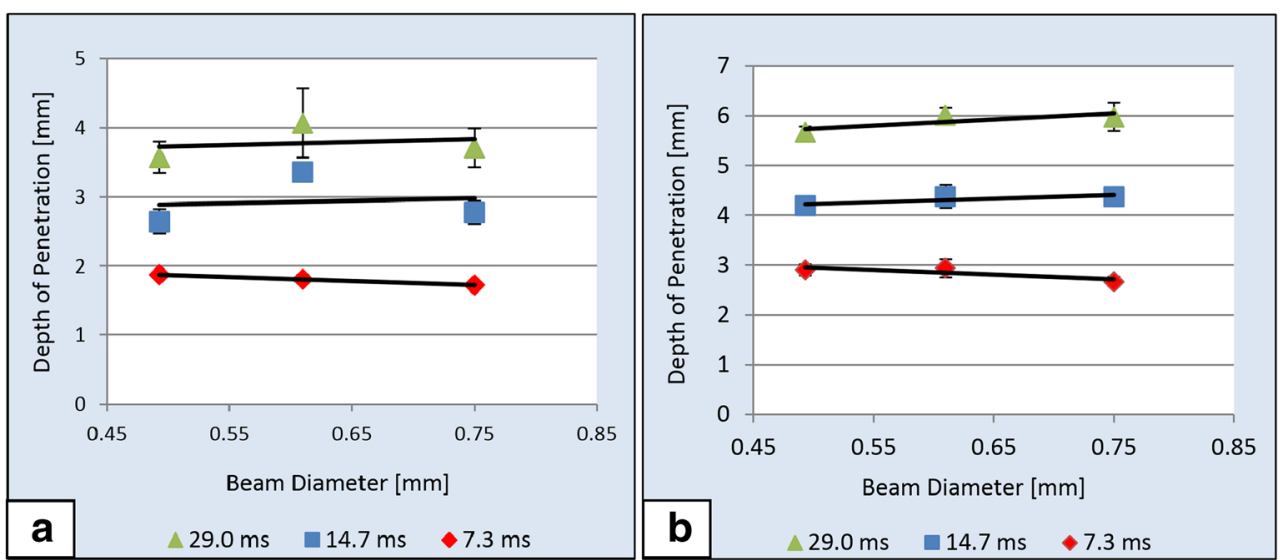
Fig. 7 Constant combinations of power factor and interaction time for different weld depths. a-c depth $=2.0 \mathrm{~mm}$. $\mathbf{d}-\mathbf{f}$ depth $=3.0 \mathrm{~mm}$. g-i depth $=4.0 \mathrm{~mm}$

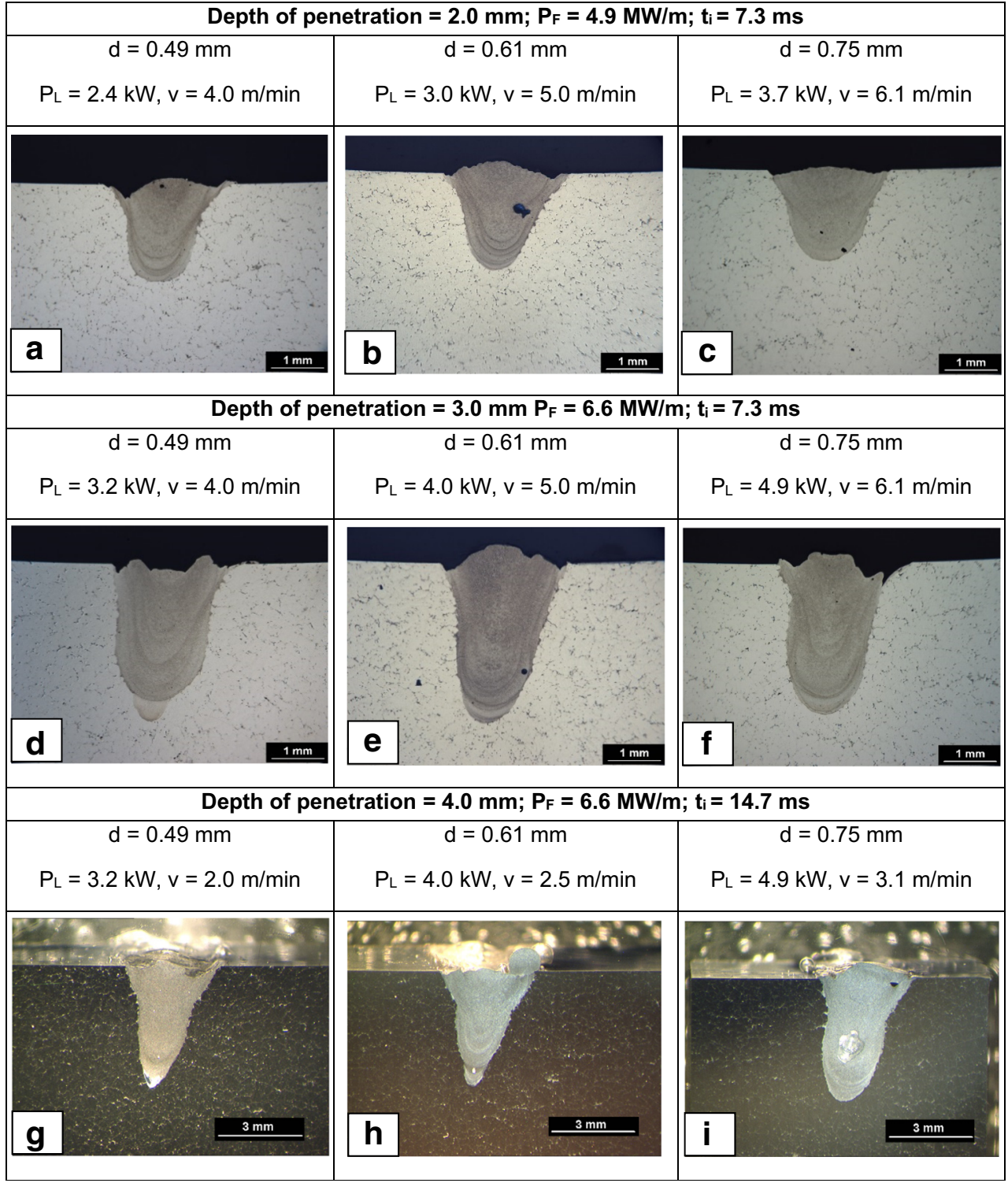

highlights the importance of the model and how it differentiates from a parametric approach of welding parameter selection, which is limited in terms of maximum power and focuscapacity of the laser system. In contrast to the traditional approach, the power factor model allows the laser user to achieve a desired weld for an intended application based on a specific combination of power factor and interaction time, transferable for different optical set-ups.

\subsubsection{Comparison of power factor vs interaction time characteristic curve for aluminium and steel}

In this section, the characteristic curve of the power factor model is compared between aluminium and steel for a constant depth of penetration. Aluminium and steel have different properties, such as melting point, thermal conductivity and boiling point, which have influence on the laser-material interaction and therefore on the weld [25]. A rectangular hyperbolic relationship between power factor and interaction time is plotted in Fig. 9, for a penetration depth of $6 \mathrm{~mm}$ for both metals. This graph compares the data from the previous work done for steel (Fig. 4) with the final results of this study for aluminium (Fig. 8). The first observation is that to achieve a weld with $6 \mathrm{~mm}$ of depth up to $50 \mathrm{~ms}$ of interaction time, higher power factor is required for steel when compared to aluminium. This means that the power applied has to be higher than for aluminium, if the beam diameter is kept constant, according to Eq. 4. On the other hand, for constant power factor, higher interaction time must be applied on steel to achieve similar penetration, which means for constant beam diameter, the travel speed has to be lowered in steel as compared to aluminium, according to Eq. 2. This can be explained 
Fig. 8 Power factor for depths of penetration of 2.0, 4.0 and $6.0 \mathrm{~mm}$ as function of interaction time for beam diameters of 0.49 , 0.61 and $0.75 \mathrm{~mm}$
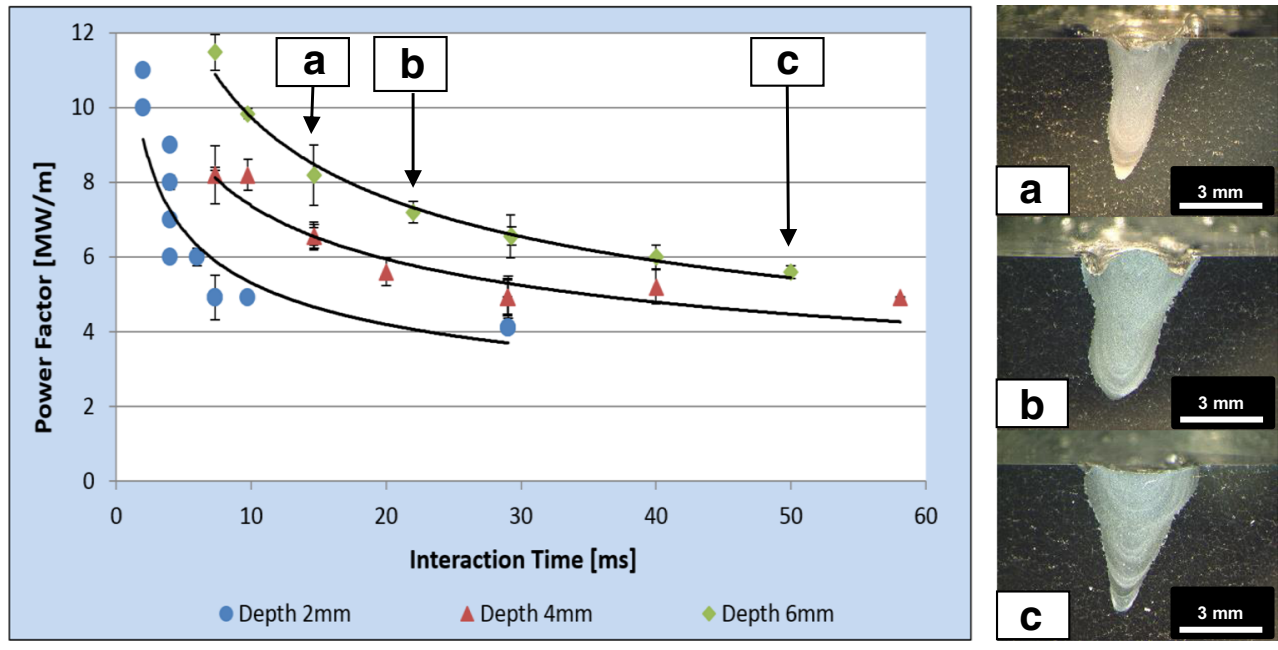

from the fact that steel (i.e. iron) has a higher melting and boiling point as compared to aluminium, and higher energy is necessary to the keyhole formation.

There is an inverse phenomena between shorter and longer interaction times. Analysing Fig. 9, the curve of aluminium is below the one for steel. Therefore, for the same values of power factor and interaction time, the penetration depth of aluminium is higher than that for steel. Nevertheless, for higher interaction times, there is an approximation of the trend lines for both metals. This could be related with the fact that conduction losses are not relevant for short interaction times [25], but they increase when the interaction time is higher. Since aluminium has higher conductivity and thermal diffusivity when compared to steel, the thermal losses become dominant in this regime, which can be seen by a wider melt pool (Fig. 8c). Consequently, to compensate these losses, more power is applied to aluminium in order to keep the penetration constant, which leads to a power factor increasing, according to Eq. 4. Hence, the gap between the trend lines gets inevitably narrower.
The thermal conductivity of the material assumes less relevance only for short interaction times, and the melting temperature of the metal is the most important physical property to take in consideration within this regime. However, for high interaction time, the capacity of aluminium to dissipate the heat is much higher than steel and the thermal conductivity overtakes the melting temperature as the most important physical property controlling the process. Therefore, based on the different thermal properties, it can be expected the application of the power factor model for other metals and the results presented in this study and in the previous work [19] can be used as a reference to achieve the welding parameters for a desired weld shape independent of the laser system and optical setup.

\section{Conclusions}

This study has shown that the power factor model is applicable to aluminium alloys.
Fig. 9 Comparison of the power factor model trend lines between aluminium and steel for a depth of penetration of $6 \mathrm{~mm}$

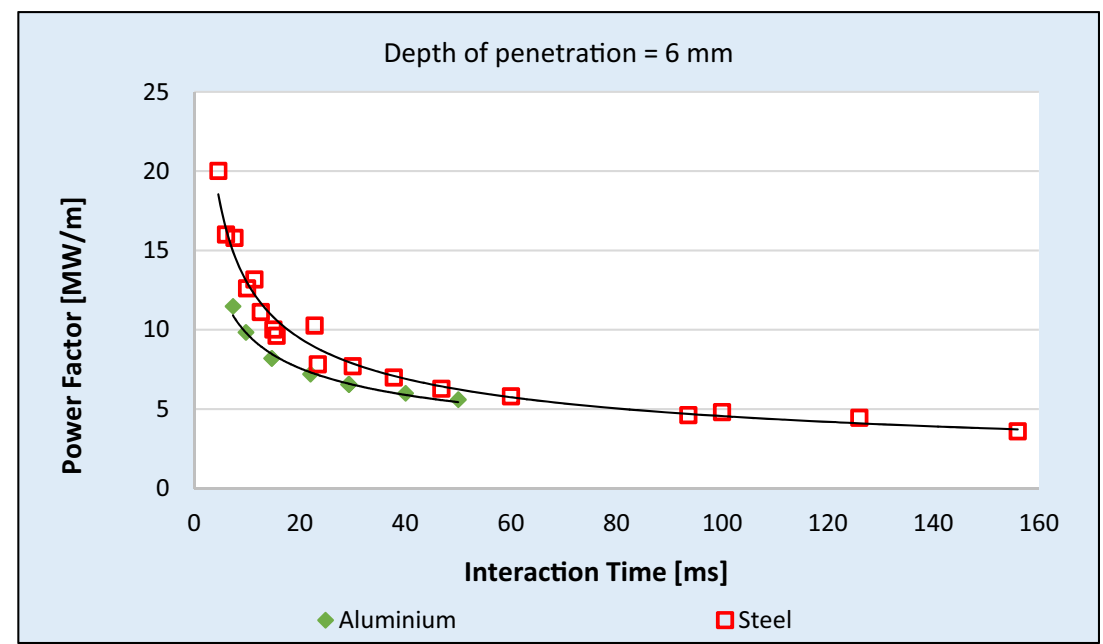


- Constant penetration depth curves against interaction time and power factor for a range of beam diameters show the same behaviour as previously observed for mild steel.

- The depth of penetration is controlled by combinations of power density and specific point energy.

- The power factor model can be used for a selection of parameters necessary for a weld of specific dimension, such as width and depth of penetration.

- Independence from the beam diameter makes the model transferable for different optical setups.

- Although the overall shape of the power factor vs interaction time characteristic curves is similar for both aluminium and steel, the effect of different physical and thermal properties could be seen in the respective profiles.

Acknowledgements The research covered in this paper was funded by the Engineering and Physical Research Council (EPSRC), the Centre for Innovative Manufacturing in Laser-based Production Processes (EP/ K030884/1).

Open Access This article is distributed under the terms of the Creative Commons Attribution 4.0 International License (http:// creativecommons.org/licenses/by/4.0/), which permits unrestricted use, distribution, and reproduction in any medium, provided you give appropriate credit to the original author(s) and the source, provide a link to the Creative Commons license, and indicate if changes were made.

\section{References}

1. Ion J (2005) Laser processing of engineering materials — principles, procedure and industrial application. Elsevier 396,495. Doi: 0750660791

2. Meco S, Pardal G, Ganguly S et al (2013) Overlap conduction laser welding of aluminium to steel. Int J Adv Manuf Technol 67:647654. doi:10.1007/s00170-012-4512-6

3. Kawahito Y, Matsumoto N, Abe Y, Katayama S (2011) Relationship of laser absorption to keyhole behavior in high power fiber laser welding of stainless steel and aluminum alloy. J Mater Process Technol 211:1563-1568. doi:10.1016/j.jmatprotec.2011. 04.002

4. Alfieri V, Caiazzo F, Sergi V (2015) Autogenous laser welding of AA 2024 aluminium alloy: process issues and bead features. Procedia CIRP 33:406-411. doi:10.1016/j.procir.2015.06.094

5. Volpp J (2016) Keyhole stability during laser welding - part II: process pores and spatters. Prod Eng Res Dev 11:9-18. doi:10. 1007/s11740-016-0705-4

6. Brock C, Tenner F, Klämpfl F et al (2013) Detection of weld defects by high speed imaging of the vapor plume. Phys Procedia 41:539543. doi:10.1016/j.phpro.2013.03.113

7. Kaplan H, AF (2011) Influence of the beam profile formulation when modeling fiber-guided laser welding. J Laser Appl 23: 42005. doi:10.2351/1.3633221

8. Volpp J, Vollertsen F (2016) Keyhole stability during laser welding - part I: modeling and evaluation. Prod Eng Res Devel 10:443-457. doi:10.1007/s11740-016-0694-3
9. Kim J, Oh S, Ki H (2015) A study of keyhole geometry in laser welding of zinc-coated and uncoated steels using a coaxial observation method. J Mater Process Technol 225:451-462. doi:10. 1016/j.jmatprotec.2015.06.029

10. Chang B, Blackburn J, Allen C, Hilton P (2016) Studies on the spatter behaviour when welding AA5083 with a Yb-fibre laser. Int J Adv Manuf Technol 1769-1776. doi: 10.1007/s00170-0157863-y

11. Assuncao E, Williams S (2014) Effect of material properties on the laser welding mode limits. J Laser Appl 26:12008. doi:10.2351/1. 4826153

12. Volpp J, Freimann D (2013) Indirect measurement of keyhole pressure oscillations during laser deep penetration welding. In: proceeding 32nd Int. Congr. Appl. Lasers electro-Optics (ICALEO), LIA Congr. Proceeding. Pp 334-340

13. Boley M, Abt F, Weber R, Graf T (2013) X-ray and optical videography for 3D measurement of capillary and melt pool geometry in laser welding. Phys Procedia 41:488-495. doi:10.1016/j.phpro. 2013.03.105

14. Schou C, Semak V, McCay T (1994) Acoustic emission at the laser weld site as an indicator of weld quality. In: proc. 13th Int. Congr. Appl. Lasers Electro-Optics. Pp 41-50

15. Geiger M, Leitz KH, Koch H, Otto A (2009) A 3D transient model of keyhole and melt pool dynamics in laser beam welding applied to the joining of zinc coated sheets. Prod Eng 3:127-136. doi:10.1007/ s11740-008-0148-7

16. Stavridis J, Papacharalampopoulos A, Stavropoulos P (2017) Quality assessment in laser welding : a critical review. Int J Adv Manuf Technol. doi:10.1007/s00170-017-0461-4

17. Berger P, Hügel H (2013) Fluid dynamic effects in keyhole welding an attempt to characterize different regimes. Phys Procedia 41:216 224. doi:10.1016/j.phpro.2013.03.072

18. Luo Y, Tang X, Lu F (2014) Experimental study on deep penetrated laser welding under local subatmospheric pressure. Int J Adv Manuf Technol 73:699-706. doi:10.1007/s00170-014-5870-z

19. Suder WJ, Williams S (2014) Optics \& laser technology power factor model for selection of welding parameters in CW laser welding. Opt Laser Technol 56:223-229. doi:10.1016/j.optlastec. 2013.08.016

20. Williams S, Suder W (2011) Use of fundamental laser material interaction parameters in laser welding. CLEO 2011 - Laser Sci to Photonic Appl 1-2.

21. Meco S, Cozzolino L, Ganguly S et al (2017) Laser welding of steel to aluminium : thermal modelling and joint strength analysis. $\mathrm{J}$ Mater Process Tech 247:121-133. doi:10.1016/j.jmatprotec.2017. 04.002

22. Pinto LA, Quintino L, Miranda RM, Carr P (2010) Laser welding of dissimilar aluminium alloys with filler materials. Weld World 54

23. Paleocrassas AG, Tu JF (2010) Inherent instability investigation for low speed laser welding of aluminum using a single-mode fiber laser. J Mater Process Technol 210:1411-1418. doi:10.1016/j. jmatprotec.2010.04.002

24. Katayama S, Nagayama H, Mizutani M, Kawahito Y (2009) Fibre laser welding of aluminium alloy. Weld Int 23:744-752. doi:10. 1080/09507110902836911

25. Suder W (2011) Study of fundamental parameters in hybrid laser welding. Cranfield University, Dissertation 
2017-07-13

Fundamental understanding of the interaction of continuous wave laser with aluminiun

\author{
Coroado, Júlio
}

Springer

Coroado J, Meco S, Williams S, et al., (2017) Fundamental understanding of the interaction of continuous wave laser with aluminium. International Journal of Advanced Manufacturing pÿTechnology, December 2017, Volume 93, Issue 9 12, pp. 31653174

http://dx.doi.org/10.1007/s00170-017-0702-6

Downloaded from Cranfield Library Services E-Repository 